\title{
The effect of performance score, prognostic nutritional index, serum neutrophil-to-lymphocyte ratio, and thrombocyte-to-lymphocyte ratio on prognosis in non-small cell lung cancer
}

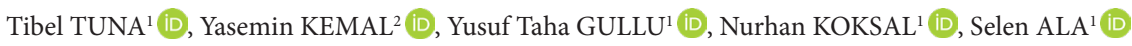 \\ ${ }^{1}$ Department of Pulmonary Medicine, School of Medicine, 19 Mayıs University, Samsun, Turkey. \\ ${ }^{2}$ Department of Medical Oncology, School of Medicine, Istinye University, Istanbul, Turkey.
}

Corresponding Author: Tibel TUNA

E-mail: tibeltuna@hotmail.com

Submitted: 27.08.2021 Accepted: 04.12.2021

\begin{abstract}
Objective: Systemic inflammatory markers and nutritional status of the patients can be helpful both in identifying high-risk cancer patients and in showing the prognosis of the disease. In this study we aimed to determine the effects of nutritional status and systemic inflammatory markers on prognosis in non-small cell lung cancer.

Patients and Methods: Patients diagnosed with non-small cell lung cancer between 2015 and 2019 were analyzed retrospectively. The prognostic nutritional index (PNI), platelet-to-lymphocyte ratio (PLR) and neutrophil-to-lymphocyte ratio(NLR) were calculated and Eastern Cooperative Oncology Group performance status (ECOG PS), and the dates of death or last follow-up were recorded. Cox regression analysis and Kaplan-Meier curves were used to analyze the effects of parameters on survival.

Results: In the study, a total of 219 patients were analyzed. 85.4\% of the patients had died. At the third step Cox regression model, ECOG 3-4 (HR:2.18), PLR (HR:1.20) and PNI (HR:1.12) predicted the survival times. Patients with PNI $>45$ had a higher median survival (495 days) than patients with $\mathrm{PNI}<45$ (314 days).

Conclusion: In order to determine the prognosis of the patients at the time of diagnosis, it is recommended to use PNI and PLR values, which can be obtained through repeated tests and evaluated at low cost, together with performance scores.

Keywords: Lung cancer, Inflammation, Nutritional status
\end{abstract}

\section{INTRODUCTION}

Lung cancer is the most common type of cancer worldwide. It is the leading cause of cancer-related deaths in men and women. Despite newly developed treatment methods, the 5 -year survival rate in advanced lung cancer is around 10-15\% [1]. Regional spread or distant metastasis is detected in most patients at the time of diagnosis [2].

It has been shown that some parameters evaluated before treatment have prognostic importance. Poor performance score, widespread stage, lactate dehydrogenase (LDH) elevation, and weight loss are considered poor prognostic factors in lung cancer. For limited-stage lung cancer, female gender, patient's age being below 70, normal LDH level, and stage 1 disease are considered good prognostic factors, while for extensive-stage lung cancer, young age, good ECOG performance score, normal

creatinine and LDH levels, single metastasis site are considered good prognostic factors in lung cancer [3,4].

Studies have shown that systemic inflammatory markers can be useful both in identifying high-risk patients and in showing the progression of the disease [5]. Studies report that the patient's nutritional status and immunity are associated with tumor spread and prognosis of the disease [6]. The prognostic nutritional index (PNI) is a measure that reflects the immunological and nutritional status of the cancer patient, which is calculated by using albumin and absolute lymphocyte value [7]. The PNI was originally developed to predict mortality and perioperative complications in patients with malnourished gastrointestinal cancer. The study showed that a low PNI value is associated with a poor prognosis [7]. Later, the relationship between PNI and survival was investigated in many cancer types

How to cite this article: Tuna T, Kemal Y, Gullu YT, Koksal N, Ala S. The effect of performance score, prognostic nutritional index, serum neutrophil-to-lymphocyte ratio, and thrombocyte-to-lymphocyte ratio on prognosis in non-small cell lung cancer.. Marmara Med J 2022: 35(1):94-99. doi: 10.5472/marumj.1065820 
such as hepatocellular carcinoma, colorectal, breast, lung, and gastric cancers. It was shown to be correlated with treatment response and long-term prognosis [8-12].

In recent studies investigating the relationship between cancerrelated inflammatory response, it has been suggested that neutrophil, B and T lymphocytes, and platelet counts play a role in tumor inflammation and immunology [13], and it has been emphasized that they are also effective in predicting the prognosis [14]. High neutrophil levels have been reported to be an indicative of mortality in metastatic melanomas [15] and renal cell carcinomas [16]. In a study conducted in patients with pancreatic cancer, it was shown that low lymphocyte count was associated with mortality [17]. By calculating the Neutrophil-Lymphocyte Ratio (NLR: Neutrophil-to-lymphocyte ratio), the prognostic feature of these two values can be used as a single indicator. A high NLR value predicts prognosis in many cancer types, including lung cancer [18]. In addition, thrombocytosis and high plateletto-lymphocyte ratio (PLR) have been reported to be associated with poor prognosis in many types of cancer [19,20].

Our study aimed to determine the effect of PNI, serum NLR and PLR on prognosis in non-small cell lung cancer.

\section{PATIENTS and METHODS}

\section{Study Population and Data Collection}

Patients diagnosed with non-small cell lung cancer between 2015 and 2019 were retrospectively analyzed. We searched the demographical, pathological, and clinical features and the laboratory data of these patients from our hospital database retrospectively.

\section{Measurements}

Baseline neutrophil, platelet (PLT) count, albumin, Eastern Cooperative Oncology Group performance status (ECOG PS), and the dates of death or last follow-up were recorded from the patients' files. Albumin value and the total lymphocyte count were used for PNI calculation. (The formula of PNI: $(0.005 \mathrm{x}$ total lymphocyte count/per $\left.\mathrm{mm}^{3}\right)+(10 \mathrm{x}$ serum albumin value $(\mathrm{g} / \mathrm{dl}))$. The patients were grouped based on the median value as low PNI (PNI<45), high PNI (PNI >45), and high PLR (PLR>167), low $\operatorname{PLR}(\mathrm{PLR}<167)$, high NLR $(\mathrm{NLR}>1.65)$ and low $(\mathrm{NLR}<1.65)$.

ECOG PS was developed by the Eastern Cooperative Oncology Group. This scale ranges from 0 to 4 ; " 0 " indicates fully functional and asymptomatic patient, "1" symptomatic but completely ambulatory, " 2 " symptomatic, $<50 \%$ in bed during the day, " 3 " symptomatic $>50 \%$ in bed but not bedbound, and " 4 " indicates bedbound status [21]. We classified patients according to ECOG 0-2 (ambulatuary) and ECOG 3-4 (unable to carry out any work activities) in our study, according to results of an European Experts Panel [22].

\section{Ethical approval}

Ethical approval of the study was obtained from the Ethical Committee of Samsun Training and Research Hospital, University of Health Sciences, with the decision number 17-2019 BADK/335.

\section{Statistical Analysis}

The categorical variables were given as numbers and percentages; continuous variables with normal distribution were presented as mean and standard deviation. Survival analysis was evaluated by the Kaplan-Meier method. The relation between survival and baseline NLR, PNR, PNI, ECOG PS were evaluated. The Cox regression analysis was used for univariate and multivariate analysis with survival-related factors. The p-value less than 0.05 was accepted as statistically significant in all comparisons. IBM SPSS statistics version 22 was used to analyze the data.

\section{RESULTS}

In our study, the data of a total of 219 patients were analyzed. Sociodemographic and clinical data of the patients are shown in Table I, and laboratory data are shown in Table II.

Table I. Sociodemographic and clinical features of the patient group

\begin{tabular}{|c|c|c|c|}
\hline & $\mathrm{n}$ & $\%$ \\
\hline \multirow[t]{2}{*}{ Gender } & Male & 182 & 83.1 \\
\hline & Female & 37 & 16.9 \\
\hline \multirow[t]{3}{*}{ Histological type } & Adenocarcinoma & 107 & 48.9 \\
\hline & Squamous carcinoma & 61 & 27.9 \\
\hline & $\begin{array}{l}\text { Non-small cell } \\
\text { (Nonclassified) }\end{array}$ & 51 & 23.3 \\
\hline \multirow[t]{4}{*}{ Cancer stage } & Stage 1 & 6 & 2.7 \\
\hline & Stage 2 & 26 & 11.9 \\
\hline & Stage 3 & 55 & 25.1 \\
\hline & \begin{tabular}{|l|} 
Stage 4 \\
\end{tabular} & 132 & 60.3 \\
\hline \multirow[t]{2}{*}{ ECOG status } & $0-2$ & 66 & 30.1 \\
\hline & $3-4$ & 154 & 69.9 \\
\hline \multicolumn{2}{|l|}{ Exitus } & 184 & 85.4 \\
\hline \multicolumn{2}{|l|}{ Age } & 219 & $63.1 \pm 9.5$ \\
\hline \multicolumn{2}{|l|}{ Survival (day) } & 184 & $\begin{array}{c}\text { Median } 272 \\
(\min 4-\max 1845) \\
\end{array}$ \\
\hline
\end{tabular}

ECOG: Eastern Cooperative Oncology Group

Table II. Laboratory data of patient group

\begin{tabular}{|l|l|}
\hline & Mean \pm SD $(\mathbf{n}: 219)$ \\
\hline Leukocyte (K/uL) & $9.54 \pm 5.34$ \\
\hline Neutrophil (K/uL) & $7.61 \pm 3.41$ \\
\hline Lymphocyte (K/uL) & $1.81 \pm 0.91$ \\
\hline Trombocyte (K/uL) & $295.43 \pm 117.30$ \\
\hline CRP $(\mathrm{mg} / \mathrm{L})$ & $14.67 \pm 9.12$ \\
\hline Albumin $(\mathbf{g r} / \mathbf{d l})$ & $3.52 \pm 0.65$ \\
\hline LDH (u/L) & $285.65 \pm 184.32$ \\
\hline NLR & $5.89 \pm 4.87$ \\
\hline PLR & $206.44 \pm 123.22$ \\
\hline PNI & $41.51 \pm 8.81$ \\
\hline
\end{tabular}

K: thousand, NLR: Neutrophile-Lymphocyte Ratio, PLR: Platelet-Lymphocyte Ratio, PNI: Prognostic Nutritional Index 
Cox regression univariate and multivariate analysis with retrospective elimination method including ECOG, NLR, PLR, PNI, and cancer stage was performed in patients who died. At the third step regression model, ECOG 3-4 (HR:2.18), PLR level (HR:1.20), PNI (HR:1.12) predicted survival times (Table III).

Table III. Cox regression analysis with ECOG, PLR, and PNI

\begin{tabular}{|l|c|c|c|c|c|c|c|}
\hline & \multicolumn{3}{|c|}{ Univariable model } & \multicolumn{4}{c|}{ Multivariable model } \\
\hline Variable & HR & $\mathbf{p}$ & $\mathbf{9 5 \%}$ CI & Variable & HR & $\mathbf{p}$ & $\mathbf{9 5 \%}$ CI \\
\hline ECOG 3-4 & 2.31 & 0.001 & $1.63-3.26$ & ECOG 3-4 & 2.18 & 0.001 & $1.53-3.08$ \\
\hline PLR & 1.63 & 0.001 & $1.21-2.20$ & PLR & 1.20 & 0.002 & $1.10-1.30$ \\
\hline PNI & 1.36 & 0.045 & $1.09-1.83$ & PNI & 1.12 & 0.044 & $1.02-1.19$ \\
\hline NLR & 1.11 & 0.226 & $0.90-2.87$ & & & & \\
\hline
\end{tabular}

CI: Confidence Interval, HR: hazard ratio, ECOG: Eastern Cooperative Oncology Group, NLR:Neutrophile-Lymphocyte Ratio, PLR: Platelet-Lymphocyte Ratio, PNI: Prognostic Nutritional Index

Analysis with Kaplan-Meier curves for PNI (Figure 1) showed that patients with $\mathrm{PNI}>45$ had a median survival of 495 days (95\% CI: 400-590), and patients with a $\mathrm{PNI}<45$ had a median survival of 314 days (95\% CI: 249-378), and a statistically significant difference was observed between the two groups $(\mathrm{p}<0.001)$ (Table IV).

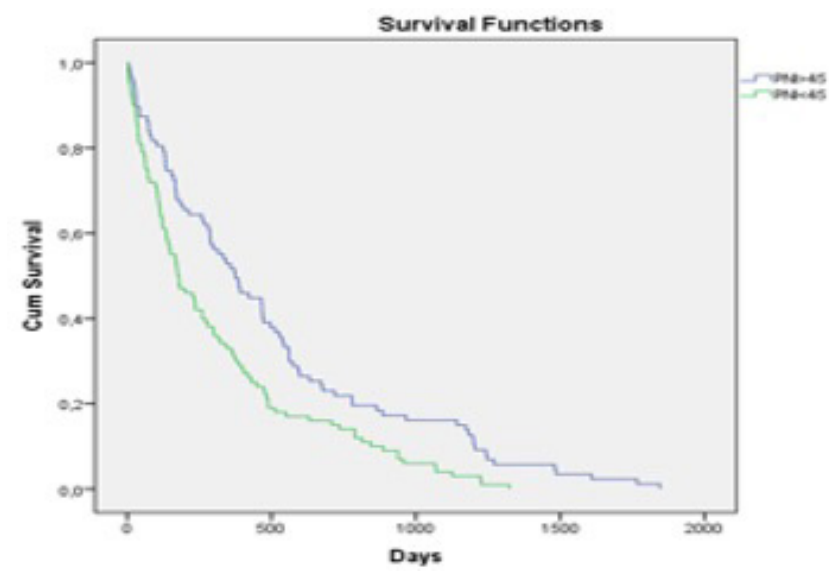

Figure 1. Kaplan-Meier curves for survival according to median PNI (PNI: Prognostic Nutritional Index)

Table IV. Median survival time for PNI levels

\begin{tabular}{|l|c|c|c|}
\hline & Median & Std. Error & 95\% Confidence Interval \\
\hline $\mathrm{PNI}>45$ & 495.10 & 80.19 & $400.05-590.15$ \\
\hline $\mathrm{PNI}<45$ & 314.00 & 44.48 & $249.41-378.58$ \\
\hline Overall & 398.25 & 29.30 & $340.81-455.69$ \\
\hline
\end{tabular}

Log-rank (Mantel-Cox) Chi-square:10.71, p:0.001

In the analysis with Kaplan-Meier curves for ECOG performance (Figure 2), patients with ECOG 0-2 had a median survival of 688 days (95\% CI: 560-815), and patients with ECOG 3-4 had a median survival of 303 days (95\% CI: 247-359), and a statistically significant difference was observed between the two groups $(\mathrm{p}<0.001)$ (Table V).

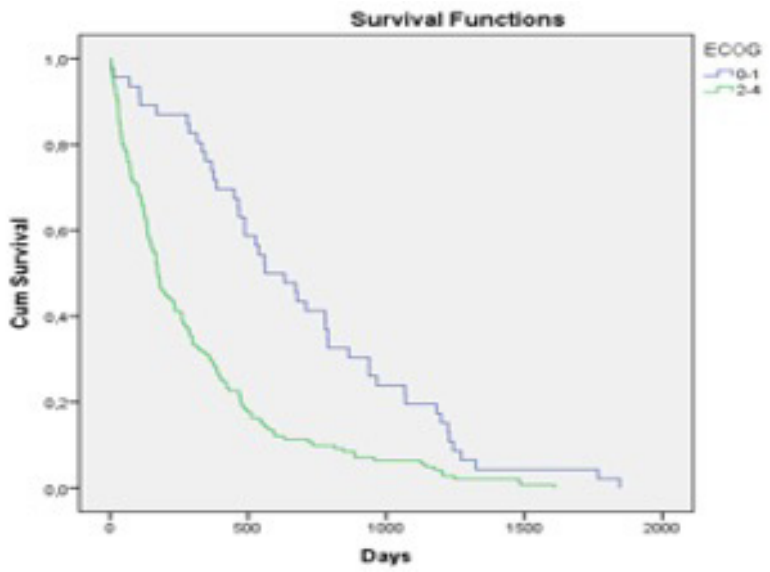

Figure 2. Kaplan-Meier curves for survival according to ECOG performance score. (ECOG: Eastern Cooperative Oncology Group 3)

Table V. Median survival time for ECOG performance

\begin{tabular}{|l|c|c|c|}
\hline & Median & Std. Error & 95\% Confidence Interval \\
\hline ECOG 0-2 & 688.00 & 65.09 & $560.53-815.68$ \\
\hline ECOG 3-4 & 303.00 & 28.44 & $247.93-359.45$ \\
\hline Overall & 398.00 & 29.30 & $340.81-455.69$ \\
\hline
\end{tabular}

Log-rank (Mantel-Cox) Chi-square:23.79, p:0.001

In analysis with Kaplan-Meier curves for PLR levels (Figure 3), patients with PLR>167 had a median survival of 184 days $(95 \%$ CI: 113-254), and patients with PLR $<167$ had a median survival of 386 days (95\% CI: 277-494), and a statistically significant difference was observed between the two groups $(\mathrm{p}=0.044)$ (Table VI).

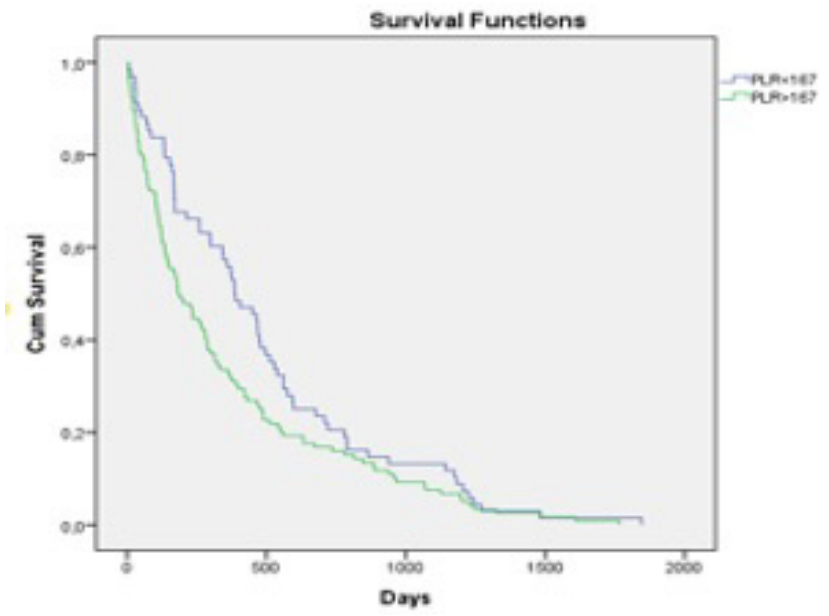

Figure 3. Kaplan-Meier curves for survival according to PLR (PLR: Platelet-Lymphocyte Ratio) 
Table VI. Median survival time for PLR levels

\begin{tabular}{|l|c|c|c|}
\hline & Median & Std. Error & 95\% Confidence Interval \\
\hline PLR $>167$ & 184.00 & 35.93 & $113.28-254.72$ \\
\hline PLR $<167$ & 386.00 & 55.17 & $277.91-494.08$ \\
\hline Overall & 272.00 & 38.30 & $196.28-347.71$ \\
\hline
\end{tabular}

Log-rank (Mantel-Cox) Chi-square:4.07, p:0.044

\section{DISCUSSION}

To date, many factors have been studied to determine the prognosis of lung cancer. The values such as PNI, NLR, PLR obtained from routine biochemical data are still being utilized in the management of cancer, mainly due to their ease of application and low cost.

In our study, we evaluated the utility of PNI, NLR, and PLR in predicting the prognosis for patients followed up for nonsmall cell lung cancer. We found that ECOG 3-4, PLR level, and PNI survival times were predicted in the model made with the retrospective elimination method in patients who died during follow-up. Similar to our study, Hong et al. have shown that PLR and PNI values were associated with survival in non-small cell lung cancer [23].

In our study, we observed that patients with low PNI had a shorter survival time. PNI is calculated using serum albumin and total lymphocyte levels, and both values indicate the severity of chronic inflammation in the body, immunity, and nutritional status. Lymphocytopenia due to systemic inflammatory reaction is a sign of impaired cellular immunity [24,25]. A low albumin level indicates that the patient has poor nutrition [26]. Both values have prognostic significance and are known to be associated with the severity of the disease and poor prognosis $[24,25]$. In a metaanalysis examining the relationship between pre-treatment PNI and survival, similar to the results of our study, it was shown that patients with low PNI had worse overall survival [27]. Bekmez et al. reported that a $\mathrm{PNI} \geq 45$ positively affects overall survival. In addition, it was found in their study that PNI $\geq 45$ and limitedstage disease were independent prognostic factors, and patients with PNI $<45$ had shorter survival [28].

It has been known for many years that poor performance scores in patients are associated with poor prognosis [29]. In a study in which patients followed up at the "National Cancer Institute" between 1973 and 1993 were examined, it was seen that ECOG performance scores of 3 and 4 negatively affected survival and were considered among the poor prognostic factors [30]. In our study, it was observed that the median survival time of patients with ECOG 0-2 was significantly higher than patients with ECOG 3-4. In the study of Torun et al., an ECOG performance score greater than one was found to be among the poor prognostic factors [31].

When we analyzed the PLR results in our study, we found that the median survival time of patients with PLR $>167$ was shorter than that for the patients with $\mathrm{PLR}<167$. In the literature, there are conflicting results between PLR level and survival. In the study by $\mathrm{Gu}$ et al., which examined 3,430 patients with advanced non-small-cell lung cancer (NSCLC), a high PLR level was shown to be associated with poor survival [32]. Another study reported that PLR might be a critical prognostic risk factor in limited-stage disease [33]. However, in a study conducted with 366 NSCLC patients in 2015, PLR could not be shown as an independent prognostic factor and was reported to be linearly related to NLR [34]. In the study of Evkan Öztürk et al., on 115 patients with lung cancer, it was observed that the association between PLR value and survival was not significant [35]. In the another study, it was shown that although there is a significant relationship between PLR and overall survival, PLR is not an independent prognostic factor [23]. Despite the conflicting results in the literature, the results of our study support that PLR can be used as a prognostic factor in patients with lung cancer.

The most important limitation of our study is its retrospective nature. Since the patients' data were analyzed retrospectively, some parameters such as comorbidities, additional medications used, presence of weight loss, and treatment modalities cannot be reached for many patients. Additional prospective studies are needed to overcome this limitation.

The use of PNI, PLR, and NLR becomes important in lung cancer, where nutrition, performance, and immune status of the patients are important in evaluating the prognosis. In order to determine the prognosis of the patients at the time of diagnosis, it is recommended to use PNI and PLR values, which can be easily repeated and evaluated at low cost, together with performance scores.

\section{Compliance with Ethical Standards}

Ethical Approval: Ethical approval of the study was obtained from the Ethical Committee of University of Health Sciences, Samsun Training and Research Hospital with the decision number 17-2019 BADK/3-35.

Financial Support: No specific funding was received.

Conflict of Interest: There are no conflicting interests.

Author Contributions:YK and TT: Literature search and study design, SA and TT: Data collection, NK and YTG: Supervision and quality control and data interpretation, TT: Drafting the article.

\section{REFERENCES}

[1] Bunn PA. Worldwide overview of the current status of lung cancer diagnosis and treatment. Arch Pathol Lab Med 2012; 136:1478-1 doi:10.5858/arpa.2012-0295-SA

[2] Jemal A, Murray T, Ward E, et al. Cancer Statistics 2005. CA: Cancer J Clin 2005;55:10-30 doi:10.3322/canjclin.55.1.10

[3] Albain KS, CrowleyJJ, Leblanc M, Livingston RB. Determinants of improved outcome in small-cell lung-cancer - an analysis of the 2,580-patient Southwest Oncology Group Data-Base. J Clin Oncol 1990;8:1563-74. doi: 10.1200/Jco.1990.8.9.1563

[4] Buccheri G, Ferrigno D, Tamburini M. Karnofsky and ECOG performance status scoring in lung cancer: a prospective, longitudinal study of 536 patients from a single institution. European journal of cancer. 1996;32:1135-1141 
[5] Hussain SP, Harris CC. Inflammation and cancer: An ancient link with novel potentials. Int J Cancer 2007;121:2373-80. doi:10.1002/ijc.23173

[6] Hayat MJ, Howlader N, Reichman ME, et al. Cancer statistics, trends, and multiple primary cancer analyses from the surveillance, epidemiology, and end results (SEER) program. Oncologist 2007 ;12:20-37. doi:10.1634/theoncologist.12-1-20

[7] Onodera T, Goseki N, Kosaki G. [Prognostic nutritional index in gastrointestinal surgery of malnourished cancer patients]. Nihon Geka Gakkai Zasshi 1984 Sep;85:1001-5.

[8] Pinato DJ, North BV, Sharma R. A novel, externally validated inflammation-based prognostic algorithm in hepatocellular carcinoma: the prognostic nutritional index (PNI). Brit J Cancer 2012; 10;106:1439-45. doi:10.1038/bjc.2012.92

[9] Nozoe T, Kimura Y, Ishida M, et al. Correlation of pre-operative nutritional condition with post-operative complications in surgical treatment for oesophageal carcinoma. Eur J Surg Oncol 2002;28:396-400. doi:10.1053/ejso.2002.1257

[10] Tokunaga R, Sakamoto Y, Nakagawa S, et al. Prognostic nutritional index predicts severe complications, recurrence, and poor prognosis in patients with colorectal cancer undergoing primary tumor resection. Dis Colon Rectum 2015;58:1048-57. doi:10.1097/Dcr.000.000.0000000458

[11] Mohri T, Mohri Y, Shigemori T, et al. Impact of prognostic nutritional index on long-term outcomes in patients with breast cancer. World J Surg Oncol.2016;14:170. doi:ARTN 17010.1186/s12957.016.0920-7

[12] Yasar HA, Bir Yucel K, Arslan C, et al. The relationship between prognostic nutritional index and treatment response in patients with metastatic renal cell cancer. J Oncol Pharm Pract 2019;26:1110-6. doi:10.1177/107.815.5219883004

[13] Schreiber RD, Old LJ, Smyth MJ. Cancer immunoediting: Integrating immunity's roles in cancer suppression and promotion. Science 2011;331:1565-70. doi:10.1126/ science. 1203486

[14] Zhang J, Huang SH, Li H, et al. Preoperative lymphocyte count is a favorable prognostic factor of disease-free survival in nonsmall-cell lung cancer. Med Oncol 2013 ;30:352 doi:ARTN 35210.1007/s12032.012.0352-3

[15] Schmidt H, Bastholt L, Geertsen P, et al. Elevated neutrophil and monocyte counts in peripheral blood are associated with poor survival in patients with metastatic melanoma: a prognostic model. Brit J Cancer 2005;93:273-8. doi:10.1038/ sj.bjc. 6602702

[16] Atzpodien J, Royston P, Wandert T, et al. Metastatic renal carcinoma comprehensive prognostic system. Brit J Cancer 2003;88:348-53. doi:10.1038/sj.bjc.6600768

[17] Fogar P, Sperti C, Basso D, et al. Decreased total lymphocyte counts in pancreatic cancer: An index of adverse outcome. Pancreas 2006;32:22-8. doi: 10.1097/01. mpa.000.018.8305.90290.50

[18] Cedres S, Torrejon D, Martinez A, et al. Neutrophil to lymphocyte ratio (NLR) as an indicator of poor prognosis in stage IV non-small cell lung cancer. Clin Transl Oncol 2012;14:864-9. doi:10.1007/s12094.012.0872-5
[19] Brown KM, Domin C, Aranha GV, et al. Increased preoperative platelet count is associated with decreased survival after resection for adenocarcinoma of the pancreas. Am J Surg 2005;189:278-2. doi:10.1016/j.amjsurg.2004.11.014

[20] Kwon HC, Kim SH, Oh SY, et al. Clinical significance of preoperative neutrophil-lymphocyte versus platelet-lymphocyte ratio in patients with operable colorectal cancer. Biomarkers 2012;17:216-22. doi:10.3109/1354750x.2012.656705

[21] Oken MM, Creech RH, Tormey DC, et al. Toxicity and response criteria of the Eastern Cooperative Oncology Group. Am J Clin Oncol 1982;5:649-56.

[22] Gridelli C, Ardizzoni A, Le Chevalier T, et al. Treatment of advanced non-small-cell lung cancer patients with ECOG performance status 2: results of an European Experts Panel. Ann Oncol 2004;15:419-26

[23] Hong X, Cui BH, Wang $M$, et al. Systemic Immuneinflammation Index, based on Platelet Counts and NeutrophilLymphocyte Ratio, is useful for predicting prognosis in small cell lung cancer. Tohoku J Exp Med 2015 ;236:297-304. doi:10.1620/tjem.236.297

[24] Ceze N, Thibault G, Goujon G, et al. Pre-treatment lymphopenia as a prognostic biomarker in colorectal cancer patients receiving chemotherapy. Cancer Chemoth Pharm 2011;68:1305-13. doi:10.1007/s00280.011.1610-3

[25] Ray-Coquard I, Cropet C, Van Glabbeke M, et al. Lymphopenia as a prognostic factor for overall survival in advanced carcinomas, sarcomas, and lymphomas. Cancer Res 2009;69:5383-91. doi:10.1158/0008-5472.Can-08-3845

[26] Eatrides J, Thompson Z, Lee JH, et al. Serum albumin as a stable predictor of prognosis during initial treatment in patients with diffuse large B cell lymphoma. Ann Hematol 2015 ;94:357-8. doi:10.1007/s00277.014.2150-9

[27] Wang ZT, Wang YJ, Zhang XM, et al. Pretreatment prognostic nutritional index as a prognostic factor in lung cancer: Review and meta-analysis. Clin Chim Acta 2018;486:303-10. doi:10.1016/j.cca.2018.08.030

[28] Bekmez E. Küçük hücreli akciğer kanserinde prognostik nutrisyonel indeksin prognoz üzerine etkisi: Tek merkez deneyimi. Namık Kemal Tip Dergisi 2020;8:158-162.

[29] Foster NR, Mandrekar SJ, Schild SE, et al. Prognostic factors differ by tumor stage for small cell lung cancer a pooled analysis of North Central Cancer Treatment Group Trials. Cancer-Am Cancer Soc 2009 15;115:2721-31. doi:10.1002/ cncr.24314

[30] Johnson DH, Turrisi AT, Chang AY, et al. Alternating chemotherapy and twice-daily thoracic radiotherapy in limited-stage small-cell lung-cancer - a pilot-study of the Eastern Cooperative Oncology Group. J Clin Oncol 1993;11:879-84. doi:10.1200/Jco.1993.11.5.879

[31] Torun E, Fidan A, Çağlayan B, et al. Küçük hücreli akciğer kanserinde prognostik faktörler. Tüberküloz ve Toraks Dergisi 2008;56:22-9.

[32] Gu XB, Sun SQ, Gao XS, et al. Prognostic value of platelet to lymphocyte ratio in non-small cell lung cancer: evidence from 
3,430 patients. Sci Rep-Uk. 2016;6:23893. doi: doi: 10.1038/ srep23893

[33] Xie D, Marks R, Zhang MR, et al. Nomograms predict overall survival for patients with small-cell lung cancer incorporating pretreatment peripheral blood markers. J Thorac Oncol 2015;10:1213-20. doi:10.1097/Jto.000.000.0000000585

[34] Wu GN, Yao YW, Bai CQ, et al. Combination of platelet to lymphocyte ratio and neutrophil to lymphocyte ratio is a useful prognostic factor in advanced non-small cell lung cancer patients. Thorac Cancer 2015;6:275-87. doi:10.1111/17597714.12178

[35] Öztürk AE, Kömürcüoğlu B, Karakurt G, et al. İleri evre akciğer kanserinde; Yaygın Kanser İnflamasyon İndeksi (ALI), serum nötrofil/lenfosit oranı (NLR), trombosit/lenfosit oranının (PLR) prognostik değeri. Journal of Izmir Chest Hospital 2021;35:134-9. doi:10.5222/igh.2021.83007 